\title{
Congenital Lateral Upper Lip Sinus: A Rare Case
}

\author{
Ankur Bhatnagar • Osman Musa • J. P. Gildiyal • \\ Mahesh Pandey
}

Received: 6 May 2009 / Accepted: 1 June 2009 / Published online: 8 March 2012

(C) Association of Surgeons of India 2012

\begin{abstract}
Congenital lateral sinuses of upper lip are malformations with uncertain etiology. These blind sinuses through orbicularis oris muscle have no intra-oral communication, with surgical excision being treatment of choice. We present our case referred to us as a patient of posttraumatic salivary fistula. Surgical management and possible etiology is discussed briefly. Also highlighted is the importance good history taking and meticulous clinical examination to accurately diagnose the entity in order to avoid expensive supportive radiological investigations.
\end{abstract}

Keywords Upper lip sinus · Lateral · Congenital · Cleft lip

\section{Introduction}

Congenital lateral lip sinus is a rare malformation, with less than 15 reported cases in English literature [1-3], presenting as a lip pit adjacent to white roll of the lip. The sinus tract extends into the mucosa with no intra oral communication. Unlike lower lip pits no specific associated anomaly or chromosomal aberrations have been documented [4] however occasional associated anomalies have been described [1]. The tract is lined by stratified squamous epithelium. Out of several theories of pathogenesis, invagination theory receives the most attention, however etiology still remains controversial [3]. We present such a patient with a congenital

A. Bhatnagar $(\bowtie)$

Department of Plastic Surgery, Sanjay Gandhi Post Graduate Institute of Medical Sciences,

Lucknow, UP, India

e-mail: bhatnagarankur2000@yahoo.com

O. Musa $\cdot$ J. P. Gildiyal • M. Pandey

Department of surgery, Era's Lucknow Medical College,

Lucknow, UP, India lateral lip sinus who was accurately diagnosed clinically and was treated satisfactorily with excision of the sinus.

\section{Case Report}

A 13 year old boy was referred to our hospital for management of a suspected salivary fistula following road traffic accident sustained 6 months back. On examination left half of upper lip was found to be swollen, indurated and tender. Examination revealed a small $2 \mathrm{~mm}$ circular opening on the vermilion, $1 \mathrm{~cm}$ lateral to midline on the left side, just below the white roll (Fig. 1).

History revealed that such pit with off and on serous discharge was present in the child since birth. There was no family history of similar condition or any other congenital anomaly. Following facial injury sustained 6 months back there have been repeated bouts of swelling and tenderness to the upper lip which had been controlled with antibiotics previously.

Intra oral examination was normal; no significant lymphadenopathy was observed, with presence of only a single discharging sinus. Based on our clinical examination we made a diagnosis of a congenital sinus of left lateral upper lip and ruled out the possibility of a salivary fistula. Probing of the tract was avoided due to local pain, edema and tenderness. Patient responded well to oral antibiotics and analgesics. One week later a sinogram confirmed the clinical diagnosis showing a well-defined sinus tract extending into the submucosal space with no intra oral connection (Fig. 2). The tract passed upwards through the lip musculature for about $2 \mathrm{~cm}$ extending up to the alar base. Plain x-ray of face was normal. Under anesthesia sinus was cannulated with a metal probe. The sinus was about $8 \mathrm{~mm}$ in depth and did not communicate with the oral cavity (Fig. 3). Sinus was then 


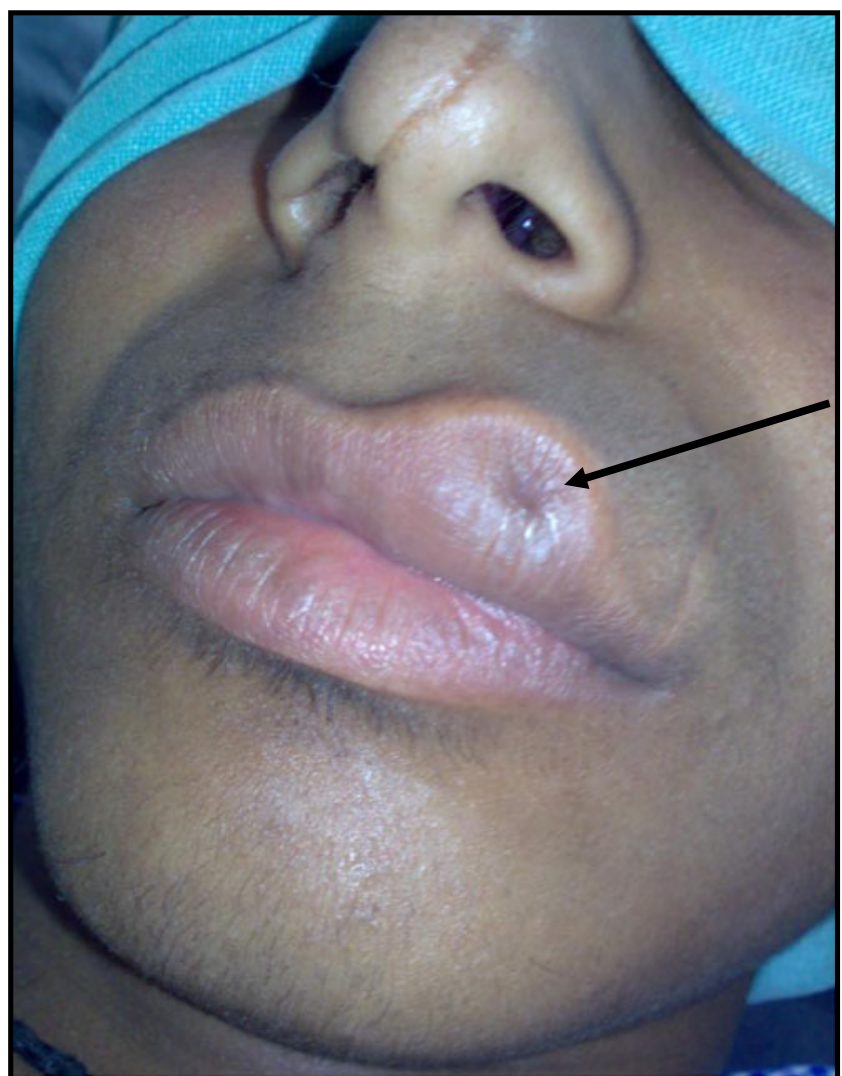

Fig. 1 Sinus in left side of upper lip

completely excised under general anesthesia using a vertical wedge incision (Fig. 4). Gentle traction was applied on the tract during dissection, which allowed complete excision in toto. The wound was then closed in layers. Post operatively wounds healed well with no recurrence (Fig. 6) after 15 months.

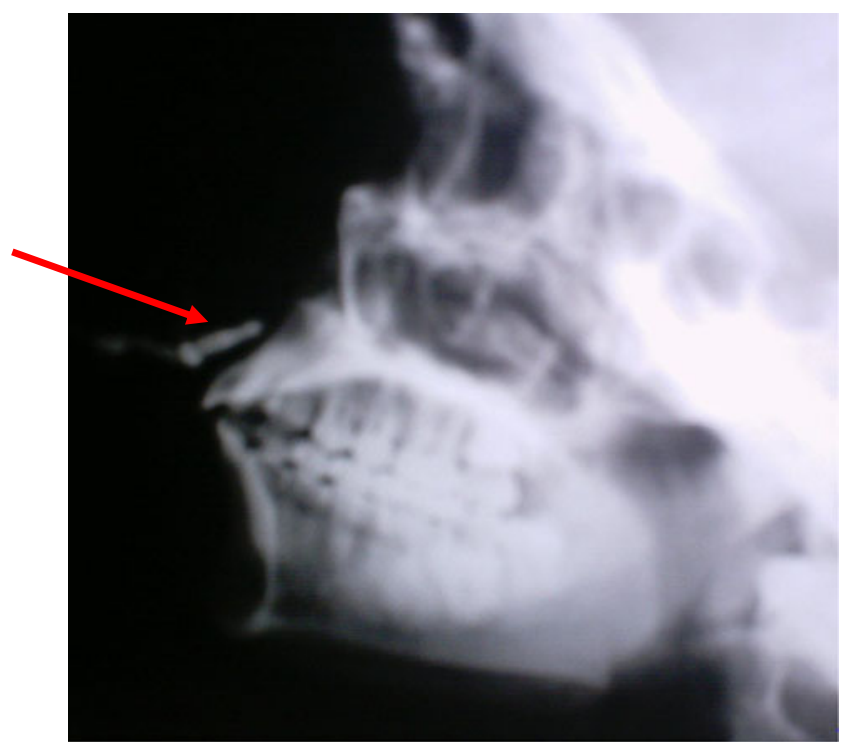

Fig. 2 Sinogram showing a blind tract with absence of bony or intra oral communication

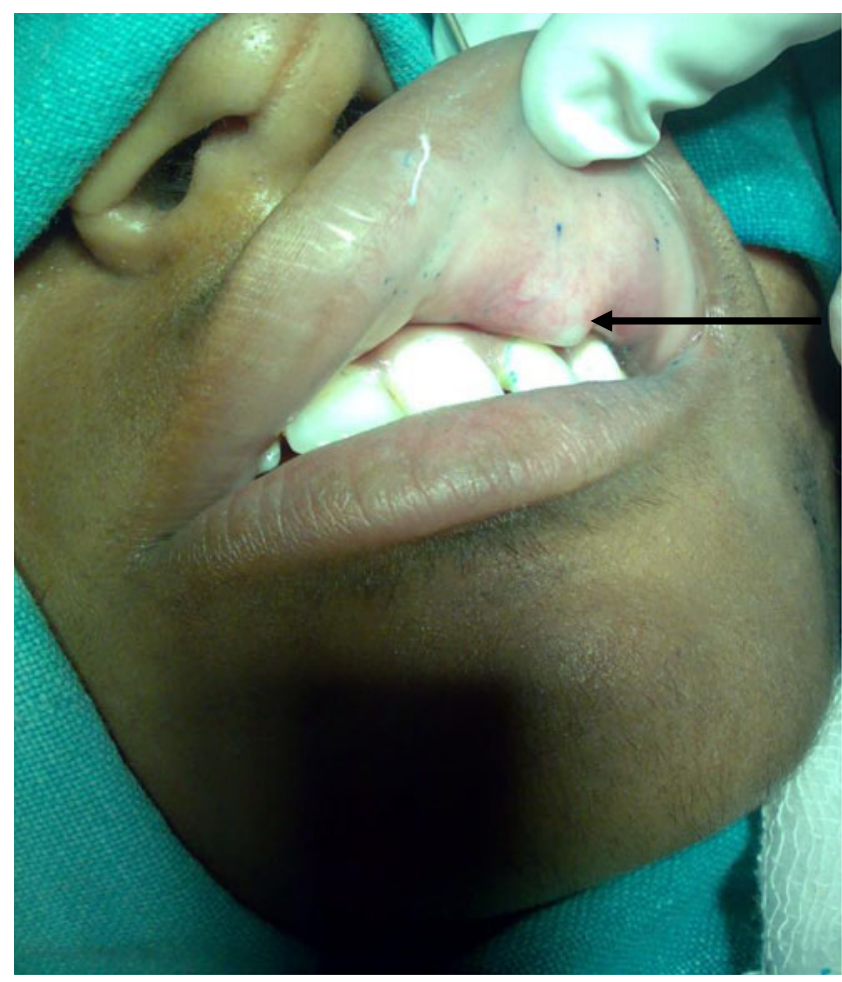

Fig. 3 Absence of intra oral communication on probing of sinus tract

Gross examination revealed a specimen $2 \mathrm{~cm}$ in length and $1.5 \mathrm{~mm}$ in diameter. Histology showed it to be a mildly keratotic stratified squamous epithelium lined sinus with presence of salivary and mucus glands. There was evidence of mild mononuclear chronic inflammation.

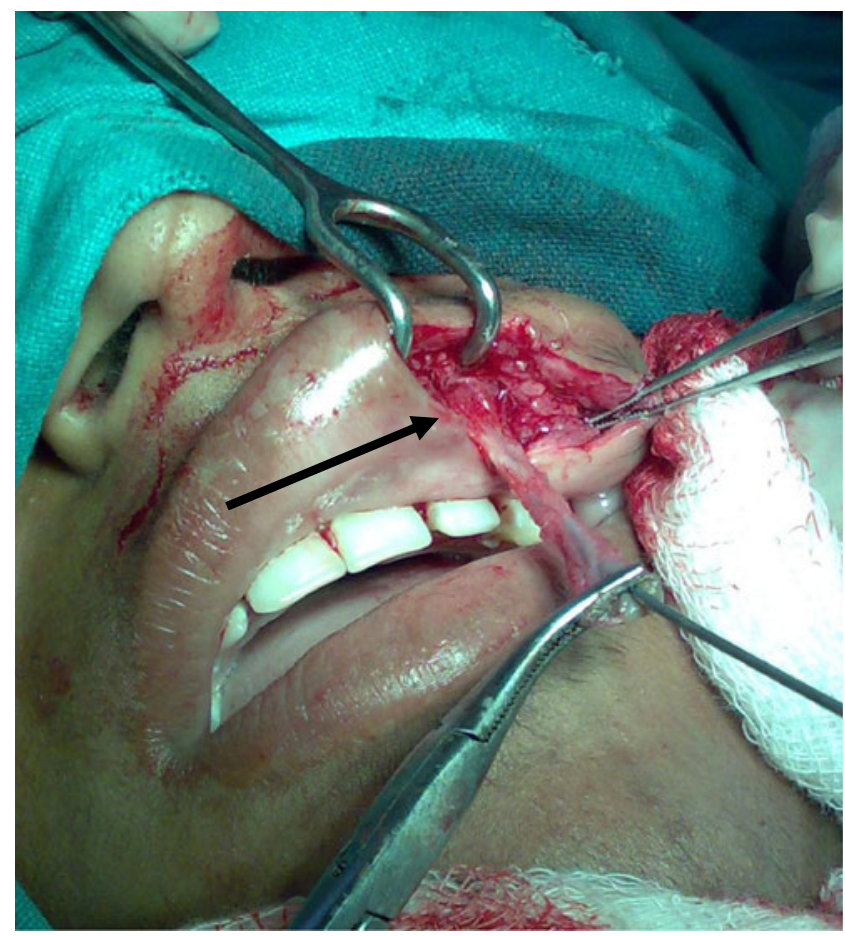

Fig. 4 Sinus excised through a vermilion incision 


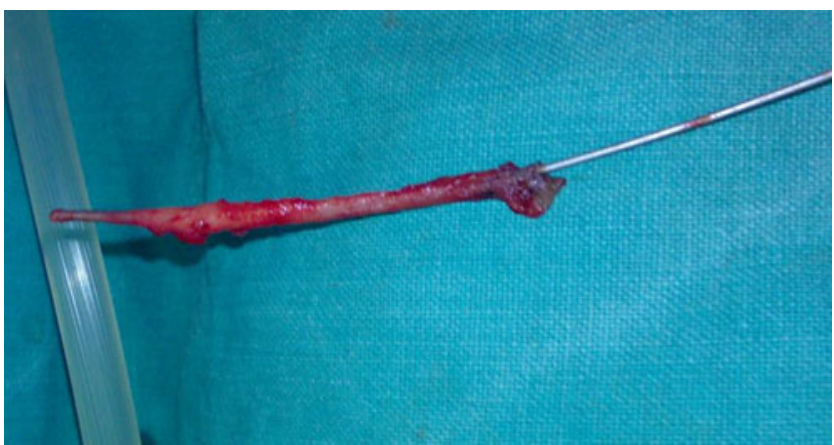

Fig. 5 Sinus excised in toto

The sinus when delivered seemed much longer than the lip itself (Figs. 5 and 6).

\section{Discussion}

A total of less than fifteen cases have been reported in English literature of which only six cases were present on the left side $[1,3]$.

Most commonly the pits open below the white role on the vermilion except in three cases where they opened just above the vermilion border $[1,3,5,6]$. The etiology of these sinuses is still obscure. They are believed to arise from embryological remnants following the union of maxillary and medial nasal processes [1, 6, 7]. Garlick et al. [8] suggested a failure of complete involution of the epithelial remnants, subsequent to their embryological fusion. This has been supported by Lee TJ et al. [3]. Raibagkar and Vyas

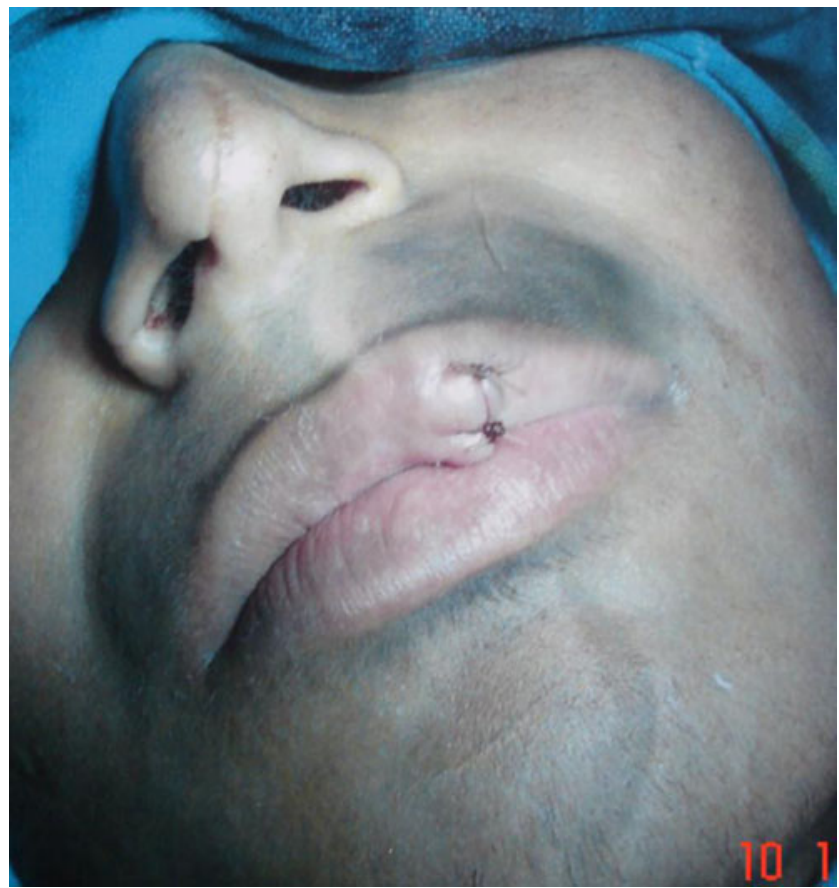

Fig. 6 Immediate post op showing good lip contour
[9], Tuncalli et al. [19] suggested that the etiology of these pits is perhaps similar to that of midline clefts and these cases may therefore be minor variant of a left sided cleft lip.

Lip sinuses arise as an aberration of the process where the outer layer of epithelium at the edge of a facial process is lost leaving an inner basal layer. Apoptosis has been suggested as a mechanism to account for the fate of these cells [16], however it has been postulated that the epithelial cells persist within the mesenchyme and lead to formation of sinuses by a process known as epithelial mesenchymal transformation [17, 18].

These sinuses are lined by stratified squamous epithelium and are generally dry. Salivary glands may open into them providing serous discharge which in our case raised a possibility of a posttraumatic salivary fistula. Our case also showed evidence of chronic dermal inflammation in form of mild mononuclear infiltration. This rare finding has also been reported earlier by Jackson [1], Clavet [10], Feurer [7] and Menendez [11]

Unlike lower lip pits very few congenital anomalies have been associated with lateral upper lip sinuses such as unilateral facial cleft [12], inclusion cyst of upper lip [13] and lateral palatal cyst [1].

Another interesting observation has been the length of the excised sinus, which seemed much longer than the lip itself. This may be due to some type of dynamic contracture along the length of the sinus. This fact has been emphasized by Illing et al. [16] in their review of midline sinuses.

Treatment of congenital lip sinus is excision. Various surgical procedures including electro coagulation, intraoral excision, vertical wedge, and transverse and z plasty have been described for its excision [9, 15]. We performed a vertical elliptical excision, which provided a wide exposure and spared the lip skin (Fig. 4). Wang [14] and Lee et al. [3] emphasized that during dissection all attached mucus glands should be removed to prevent the formation of mucoid cyst and the closure should be in layers with good muscle approximation.

The aim of presentation is to highlight a rare clinical entity. A high index of suspicion and detailed clinical examination are the pre-requisites for correct diagnosis and appropriate surgical management of this condition. The point to be stressed is that astute and meticulous clinical examination can make redundant expensive supportive radiological investigations such as magnetic resonance imaging and CT scans.

\section{Conclusion}

Lateral congenital lip sinus is a rare entity with disputed etiology. They most probably arise from the embryological remnants of ectoderm embedded in the mesodermal elements 
of the lip hence may be a minor form of cleft lip. We believe that, in such cases, it is reasonable to proceed directly to the operating room without first obtaining additional studies such as MRI. It is very important, however, that the surgeon not hesitate to obtain these additional preoperative investigations should there be a less clear clinical diagnosis, or if there is concern that the lesion could be originating from an anatomical structure other than thought of. In the case described in this article, we did not feel that these additional diagnostic tests were required, and we certainly appreciate the fact that additional diagnostic measures, in particular MRI, can be very useful in regard to refining the diagnosis and surgical plan in the preoperative setting. Ultimately, the decision to use additional preoperative tests, or to proceed to the operating room for direct inspection and excision, hinges on the individual surgeon's judgment. A good history and clinical examination is the key to correct diagnosis and complete excision of the sinus is the treatment of choice.

\section{References}

1. Rifaat M, Jackson IT, Celebilor O (1998) The lateral upper lip sinus: case report and review of literature. Eur J Plast Surg 21:98-100

2. Illing HM, Field D, McNamara CM, Sandy JR (1999) Congenital sinus of upper lip: a case report. Int J Oral Maxillofacial Surg 28:29-30

3. Lee TJ, Bin CW, Koh CS (2003) Congenital sinus of upper lip. J Korean Cleft Palate-Craniofac Assoc 4(1):45-47

4. Grenman R, Salo H, Rintala A (1985) Midline sinus of upper lipa case report. Scand J Reconstruc Surg 19:215
5. Kriens O, Schmidt H, Mueller Driver O (1973) Congenital lateral fistula of upper lip: a case report. J Maxillofac Surg 1:122

6. Parcelier A, Lacoste A (1914) Fistule congenitale de la levre superieure. Arch Gen Chir Paris 8:292

7. Feurer G (1893) Angeborene Oberlippenfistel. Arch Klin Chir $46: 35$

8. Garlick JA, Calderon S, Metzker A, Rotem A, Abramovici A (1989) Simultaneous occurrence of a congenital lateral upper lip sinus and congenital gingival cyst. A case report and discussion of pathogenesis. Oral Surg Oral Med Oral Pathol 68(3):317-323

9. Raibagkar S, Vyas UH (1986) Lateral congenital sinus of the upper lip. Indian J Plast Surg 19(1):50-52

10. Clavet EGM (1889) Des Fistules et des cysts congenitaux de la levre superieure (These No. 42) Bordeaux [cited by Rifaat M et al] [1]

11. Menendez OR (1969) Congenital pit of upper lip. Oral Surg 27:441

12. Kraske P (1887) Zur Casuistick der Retardierten intrauterinen Verschmeizung von Gesichtsspalten. Arch Klin Chir 20:396 [cited by Rifaat $\mathrm{M}$ et al] [1]

13. Radcliff W (1940) Rare congenital malformations of the lip. Br J Plast Surg 28:239

14. Wang MKH, Macomber WB (1956) Congenital lip sinuses. Plast Reconstr Surg 18:319

15. Calderon S, Garlick JA (1988) Surgical excision of a congenital lateral fistula of the upper lip. An intraoral approach. J Cranio Maxillofac Surg 16:46

16. Illing HM, Field D, McNamara CM, Sandy JR (1999) Congenital sinuses of the upper lip. A case report. Int J Oral Maxillofac Surg 28:29-30

17. Hay ED (1995) An overview of epithelial-mesenchymal transformation. Acta Anat 154:8-20

18. Hoffman LA (1971) Congenital lip sinus: aspects and their relationships to cleft lip and palata. Br J Plast Surg 24:241-246

19. Tuncalli D et al (2006) Two cases of congenital midline upper lip sinuses associated with miscellaneous deformities. J Oral Maxillofac Surg 64:734-737 